\title{
Increased Prevalence of Polyneuropathy in Parkinson's Disease Patients: An Observational Study
}

\author{
Christian Conradt ${ }^{\mathrm{a}, *}$, Dianlin Guo $^{\mathrm{a}}$, Anca Miclea ${ }^{\mathrm{b}}$, Thomas Nisslein ${ }^{\mathrm{b}}$, Chaim Ismail $^{\mathrm{c}}$, \\ Krai Chatamra a and Frank Andersohn ${ }^{\mathrm{d}}$ \\ ${ }^{a}$ AbbVie Inc., North Chicago, IL, USA \\ b Abbott Laboratories, EDP Global Pharmacovigilance, Hannover, Germany \\ ${ }^{\mathrm{c}} P B$ Consulting Network, Oberpfalz, Germany \\ ${ }^{\mathrm{d}}$ Institute for Social Medicine, Epidemiology, and Health Economics, Charité University Medical Center, \\ Frank Andersohn Consulting and Research Services, Berlin, Germany
}

Accepted 23 October 2017

\begin{abstract}
.
Background: The independent contribution of levodopa exposure and Parkinson's disease (PD) to the risk of polyneuropathy is not established.

Objective: This study investigated whether patients with newly diagnosed PD without previous exposure to antiparkinsonian drugs have higher prevalence of polyneuropathy than the general population.

Methods: Using the UK General Practice Research Database, presence of polyneuropathy in the previous 3 years was assessed.

Results: Of 5089 PD patients and 19,897 controls, polyneuropathy was confirmed in 15 PD patients $(0.29 \%)$ and 24 controls $(0.12 \%)$. Polyneuropathy prevalence was 2.4 -fold higher in PD patients than controls.

Conclusions: In this observational study, PD patients had a higher prevalence of preexisting polyneuropathy that cannot be explained by adverse effects of antiparkinsonian drugs.
\end{abstract}

Keywords: Polyneuropathy, Parkinson's disease, observational study

\section{INTRODUCTION}

Previous studies have reported a higher prevalence of polyneuropathy in patients with Parkinson's disease (PD) than in control subjects due to vitamin B12 deficiency caused by levodopa exposure [1-4]. It has been noted that, due to the high correlation between cumulative levodopa exposure and PD severity, separating the role of these two factors on the risk of neuropathy is challenging [5].

${ }^{*}$ Correspondence to: Christian Conradt, 701 Brookstone Rd, Grayslake, IL, USA. Tel.: +1 224443 0926; E-mail: christian@ conradt.info.
To address this methodological problem, the present study aimed to investigate whether patients with newly diagnosed PD (i.e., those patients without a history of exposure to antiparkinsonian drugs) have a higher prevalence of polyneuropathy (PNP) than that observed in general population controls without PD.

\section{METHODS}

\section{Study design and data source}

In this population-based observational study, patients with newly diagnosed PD and matched 
controls without PD were compared with respect to the presence of PNP in the previous 3 years. Data source was the UK General Practice Research Database (GPRD), consisting of the electronic patient records of about 10 million patients from more than 500 general practices in the United Kingdom. A number of observational studies in PD patients were performed with the GPRD [6], and several validation studies have demonstrated completeness and validity of the database [7, 8]. The study was reviewed for ethical and scientific merit, and was approved by the Independent Scientific Advisory Committee of the GPRD.

\section{Identification of PD patients and controls}

For PD patients, the date of the first diagnosis of PD was defined as the index date. Inclusion criteria indicated that patients: (1) had to be at least 18 years of age, (2) had at least 3 years of available persontime before the index date, (3) had not received more than one anti-Parkinsonian drug prescription in the 3 years before the index date, and (4) had at least two prescriptions of anti-Parkinsonian drugs after the index date. For each PD patient, up to four controls without PD were matched by sex, age, and general practice. Exclusion criteria indicated that patients: (1) had medical conditions known to be associated with neuropathy (e.g., diabetes, alcohol abuse), (2) were prescribed drugs known to cause neuropathy within 3 years before the index date, and (3) were prescribed drugs known to cause Parkinsonism within 180 days preceding the index date.

\section{Definition and identification of PNP}

In PD patients and controls, all diagnoses of primary polyneuropathy without an underlying medical condition as well as potential vitamindeficiency-related neuropathies within 3 years preceding the index date were identified. As previous studies indicated that vitamin B6, vitamin B12, and/or folate deficiencies might play an important role in PD-associated neuropathy [1-4], these types of polyneuropathy were included in the study definition of PNP.

All subjects with potential PNP were validated independently and blinded to case status by two physicians (A.M. and C.I.). In the rare case of disagreement, the patient record was discussed between the reviewers. PNP was considered as confirmed, if there was no other compelling reason for PNP and at least one of the following criteria were met: PNP diagnosis was made by a specialist, PNP was a hospital discharge diagnosis, or PNP was diagnosed in the context of nerve conduction studies; there was initiation of treatment for PNP; or PNP diagnosis was repeated in medical records $>1$ month after initial diagnosis.

\section{Statistical analysis}

Conditional logistic regression analysis was used to calculate odds ratios for the association between PNP and PD. As potential confounders were eliminated by study design due to matching and exclusion of other potential causes of polyneuropathy, no other variables were considered. Analyses stratified by sex and age were performed. To evaluate the impact of the validation procedure on the study results, a sensitivity analysis included all potential cases of PNP, irrespective of a diagnosis confirmed in the validation process. In another sensitivity analysis, all persontime prior to the index date (instead of 3 years) was considered to assess presence of PNP. All analyses were performed using SAS 9.1 (SAS Institute Inc., Cary, NC, USA.).

\section{RESULTS}

A total of 5132 patients with incident PD, who fulfilled all inclusion and exclusion criteria were identified. Of these, 5089 patients $(99.2 \%)$ had at least one matched control and four controls were available for 95.2\% PD patients (Table 1).

A total of $20 \mathrm{PD}$ patients $(0.39 \%)$ and 40 controls $(0.20 \%)$ had a diagnosis indicating PNP within 3 years prior to the index date. After manual record review, 15 PD patients and 24 controls were classified as patients with confirmed PNP. The prevalence

Table 1

Demographic characteristics of PD patients and matched controls

\begin{tabular}{lcc}
\hline Characteristic & $\begin{array}{c}\text { PD patients, } n(\%) \\
(n=5089)\end{array}$ & $\begin{array}{c}\text { Matched controls, } n(\%) \\
(n=19,897)\end{array}$ \\
\hline Males & $3156(62)$ & $12,261(61.6)$ \\
$<60$ years & $383(7.5)$ & $1530(7.7)$ \\
60-69 years & $747(14.7)$ & $2985(15.0)$ \\
70-79 years & $1206(23.7)$ & $4761(23.9)$ \\
$\geq 80$ years & $820(16.1)$ & $2985(15.0)$ \\
Females & $1933(38.0)$ & $7636(38.4)$ \\
$<60$ years & $184(3.6)$ & $736(3.7)$ \\
60-69 years & $388(7.6)$ & $1552(7.8)$ \\
$70-79$ years & $724(14.2)$ & $2876(14.5)$ \\
$\geq 80$ years & $637(12.5)$ & $2472(12.4)$ \\
\hline
\end{tabular}

PD, Parkinson's disease. 
of PNP was increased 2.4-fold in patients with incident PD compared with general population controls (odds ratio $[\mathrm{OR}]=2.41 ; 95 \%$ confidence interval [CI], 1.17-4.81). There was no indication that age or sex acted as effect modifiers, but these analyses were limited by the low number of patients with PNP (Table 2).

The sensitivity analysis that accounted for all potential PNP (irrespective of validation results) revealed similar results $(\mathrm{OR}=1.95 ; 95 \% \mathrm{CI}$, 1.08-3.42). The sensitivity analysis that expanded the assessment period for PNP to the total available person-time also revealed results similar to the main analysis $(\mathrm{OR}=1.96$; $95 \% \mathrm{CI}, 1.23-3.08$ for potential $\mathrm{PNP}$ and $\mathrm{OR}=2.32 ; 95 \% \mathrm{CI}, 1.19-4.40$ for confirmed PNP).

\section{DISCUSSION}

In this observational study, patients with incident PD had a higher prevalence of preexisting PNP than matched general population controls without PD. Sensitivity analyses revealed that the results were robust with respect to the effects of case validation and with respect to the time window used to account for PNP.

Previous studies on the association of PD and polyneuropathy focused on patients with known PD and reported strong associations of levodopa treatment and presence of polyneuropathy in these patients [2-4]. In contrast, the present study considered the person-time before PD treatment was initiated, so that the increased frequency of PNP cannot be explained by adverse effects of anti-Parkinsonian drugs. One study assessed the prevalence of PNP in untreated patients with PD; however, this study did not make comparisons with age-matched patients without PD [2]. Other studies have indicated that there might be a link between disorders of the peripheral nervous system and PD. A case-control study on the history of Bell's Palsy in patients with incident $\mathrm{PD}$, compared with controls without $\mathrm{PD}$, revealed an increased frequency of Bell's Palsy in PD patients [9]. A histopathological study revealed that PD patients had a significant loss of epidermal nerve fibers and Meissner corpuscles, compared with healthy controls [10]. Peripheral neuropathy has been described in association with early onset genetic PD due to mutations of the parkin gene [11, 12], which indicates a link between central and peripheral neuronal degeneration at least in these subgroups of PD patients.

This observational study has some potential limitations that should be considered. As the assessment of PNP was based on clinical diagnoses, some patients might have been considered as PNP cases by error. However, one would expect the results to be biased towards the null (i.e., no association) in case of non-differential misclassification. The absolute prevalence of PNP in this study was low and most probably, active screening for PNP would have substantially increased the prevalence. This, however, does not explain the increased odds ratio observed

Table 2

Prevalence of PNP in PD patients and matched controls

\begin{tabular}{|c|c|c|c|}
\hline Characteristic & $\begin{array}{l}\text { No. of PD patients } \\
\text { PNP/total No. of } \\
\text { patients }(\%) \\
(n=5089)\end{array}$ & $\begin{array}{l}\text { No. of controls with } \\
\text { PNP/total No. of } \\
\text { controls }(\%) \\
(n=19,897)\end{array}$ & OR $(95 \% \mathrm{CI})$ \\
\hline All patients & $15 / 5089(0.29)$ & $24 / 19,897(0.12)$ & $2.41(1.17-4.81)$ \\
\hline$<60$ years & $1 / 567(0.18)$ & $0 / 2266(0)$ & $\mathrm{NC}$ \\
\hline $60-69$ years & $3 / 1135(0.26)$ & $5 / 4537(0.11)$ & $2.40(0.37-12.34)$ \\
\hline $70-79$ years & $6 / 1930(0.31)$ & $9 / 7637(0.12)$ & $2.67(0.78-8.39)$ \\
\hline$\geq 80$ years & $5 / 1457(0.34)$ & $10 / 5457(0.18)$ & $1.81(0.47-5.91)$ \\
\hline Males & $11 / 3156(0.35)$ & $15 / 12,261(0.12)$ & $2.79(1.15-6.54)$ \\
\hline$<60$ years & $0 / 383(0)$ & $0 / 1530(0)$ & $\mathrm{NC}$ \\
\hline $60-69$ years & $3 / 747(0.40)$ & $5 / 2985(0.17)$ & $2.40(0.37-12.34)$ \\
\hline $70-79$ years & $4 / 1206(0.33)$ & $5 / 4761(0.11)$ & $3.20(0.64-14.87)$ \\
\hline$\geq 80$ years & 4/820 (0.49) & $5 / 2985(0.17)$ & $2.76(0.53-13.21)$ \\
\hline Females & $4 / 1933(0.21)$ & $9 / 7636(0.12)$ & $1.78(0.40-6.37)$ \\
\hline$<60$ years & $1 / 184(0.54)$ & $0 / 736(0)$ & $\mathrm{NC}$ \\
\hline $60-69$ years & $0 / 388(0)$ & $0 / 1552(0)$ & $\mathrm{NC}$ \\
\hline $70-79$ years & $2 / 724(0.28)$ & $4 / 2876(0.14)$ & $2.00(0.18-13.96)$ \\
\hline$\geq 80$ years & $1 / 637(0.16)$ & $5 / 2472(0.20)$ & $0.80(0.02-7.15)$ \\
\hline
\end{tabular}


in this study. It cannot be excluded that some PD patients were misdiagnosed as having PNP before the diagnosis of PD was made. As the main analysis was based on confirmed PNP, and the extension of the assessment period beyond 3 years revealed robustness of the results, it seems unlikely that this potential source of bias has substantially affected the results. Due to the observational nature of the study, it was not possible to retrospectively classify PNP cases into those with or without causal relationship to vitamin B/folate deficiencies, nor was it possible to perform a sensitivity analysis restricted to PNP cases without relationship to these deficiencies.

Additional studies are warranted to better understand the linkage between PD and PNP. A recent study using confocal corneal microscopy demonstrated that newly diagnosed, untreated PD patients had a higher rate of PNP than controls [13], further confirming the results of this observational study. Longitudinal studies using confocal corneal microscopy in patients with PD before and after treatment could help to further elucidate the role of anti-PD treatment in PNP.

\section{ACKNOWLEDGMENTS}

This study was funded by AbbVie, Inc. AbbVie participated in the study design, research, data collection, analysis, and interpretation of data, writing, reviewing, and approving the manuscript. Medical writing assistance, funded by AbbVie, was provided by Kelly M Cameron, PhD, ISMPP CMPP ${ }^{\mathrm{TM}}$, of JB Ashtin, who, on behalf of the authors, provided assistance in implementing author revisions throughout the editorial process. The authors would like to thank Maurizio Facheris, an AbbVie employee, for his clinical insight in the development of this manuscript.

\section{CONFLICTS OF INTEREST}

Dianlin Guo is an employee of AbbVie Inc., and may hold stock and/or stock options.

Anca Miclea is an employee of Abbott Laboratories and may hold stock and/or stock options.

Thomas Nisslein is an employee of Abbott Laboratories and may hold stock and/or stock options. He is also a speaker for RAPS.
Christian Conradt, Chaim Ismail, and Krai Chatamra were previously employed by Abbott/ AbbVie at the time of the study.

Frank Andersohn worked as a consultant for Abbott, AstraZeneca, Bayer, Boehringer Ingelheim, GlaxoSmithKline, Lundbeck, Mundipharma, and Nordmark.

\section{REFERENCES}

[1] Rajabally YA, Martey J (2011) Neuropathy in Parkinson disease: Prevalence and determinants. Neurology 77, 19471950.

[2] Rajabally YA, Martey J (2013) Levodopa, vitamins, ageing and the neuropathy of Parkinson's disease. J Neurol 260, 2844-2848.

[3] Toth C, Brown MS, Furtado S, Suchowersky O, Zochodne D (2008) Neuropathy as a potential complication of levodopa use in Parkinson's disease. Mov Disord 23, 1850-1859.

[4] Toth C, Breithaupt K, Ge S, Duan Y, Terris JM, Thiessen A, Wiebe S, Zochodne DW, Suchowersky O (2010) Levodopa, methylmalonic acid, and neuropathy in idiopathic Parkinson disease. Ann Neurol 68, 28-36.

[5] Nolano M, Provitera V, Lanzillo B, Santoro L (2011) Neuropathy in idiopathic Parkinson disease: An iatrogenic problem? Ann Neurol 69, 427-428; author reply 428-429.

[6] Schade R, Andersohn F, Suissa S, Haverkamp W, Garbe E (2007) Dopamine agonists and the risk of cardiac-valve regurgitation. N Engl J Med 356, 29-38.

[7] Khan NF, Harrison SE, Rose PW (2010) Validity of diagnostic coding within the General Practice Research Database: A systematic review. Br J Gen Pract 60, e128-e136.

[8] Hernan MA, Logroscino G, Rodriguez LA (2004) A prospective study of alcoholism and the risk of Parkinson's disease. J Neurol 251(suppl 7), 14-17.

[9] Savica R, Bower JH, Maraganore DM, Grossardt BR, Rocca WA (2009) Bell's palsy preceding Parkinson's disease: A case-control study. Mov Disord 24,1530-1533.

[10] Nolano M, Provitera V, Estraneo A, Selim MM, Caporaso G, Stancanelli A, Saltalamacchia AM, Lanzillo B, Santoro L (2008) Sensory deficit in Parkinson's disease: Evidence of a cutaneous denervation. Brain 131, 1903-1911.

[11] Abbruzzese G, Pigullo S, Schenone A, Bellone E, Marchese R, Di Maria E, Benedetti L, Ciotti P, Nobbio L, Bonifati V, Ajmar F, Mandich P (2004) Does parkin play a role in the peripheral nervous system? A family report. Mov Disord 19, 978-981.

[12] Okuma Y, Hattori N, Mizuno Y (2003) Sensory neuropathy in autosomal recessive juvenile parkinsonism (PARK2). Parkinsonism Relat Disord 9, 313-314.

[13] Podgorny PJ, Suchowersky O, Romanchuk KG, Feasby TE (2016) Evidence for small fiber neuropathy in early Parkinson's disease. Parkinsonism Relat Disord 28, 94-99. 